\title{
Effects of the carbonic anhydrase VI gene polymorphisms on dental caries: A meta-analysis
}

\section{Wpływ polimorfizmów genu anhydrazy węglanowej VI \\ na próchnicę zębów - metaanaliza}

\author{
Omer Hatipoglul, ${ }^{1, A-F}$, Faruk Saydam ${ }^{2, B, E, F}$ \\ ${ }^{1}$ Department of Restorative Dentistry, Kahramanmaraş Sütçü Imam University, Turkey \\ ${ }^{2}$ Department of Medical Biology, Recep Tayyip Erdoğan University, Rize, Turkey \\ A - research concept and design; $\mathrm{B}$ - collection and/or assembly of data; $\mathrm{C}$ - data analysis and interpretation; \\ $D$ - writing the article; $\mathrm{E}$ - critical revision of the article; $\mathrm{F}$ - final approval of the article
}

Address for correspondence

Omer Hatipoglu

E-mail: ohatipoglu@ksu.edu.tr

Funding sources

None declared

Conflict of interest

None declared

Received on May 30, 2019

Reviewed on June 10, 2019

Accepted on July 3, 2019

Published online on December 30, 2019

Cite as

Hatipoglu 0, Saydam F. Effects of the carbonic anhydrase VI gene polymorphisms on dental caries: A meta-analysis. Dent Med Probl. 2019;56(4):395-400. doi:10.17219/dmp/110453

DOI

10.17219/dmp/110453

Copyright

○ 2019 by Wroclaw Medical University

This is an article distributed under the terms of the

Creative Commons Attribution 3.0 Unported License (CC BY 3.0)

(https://creativecommons.org/licenses/by/3.0/)

\begin{abstract}
Background. Carbonic anhydrase VI (CA VI) is considered to greatly participate in the buffering of saliva, ion transport, the regulation of pH, secretory processes, and saliva production. Various studies have been conducted to investigate the relationship between CAVI and dental caries.

Objectives. The goal of this study was to make a meta-analysis of studies that examined the effects of the CA V/ gene polymorphisms on dental caries.

Material and methods. The Preferred Reporting Items for Systematic Reviews and Meta-Analyses (PRISMA) statement guide was followed. Electronic databases (PubMed, Web of Science, Scopus, and Cochrane Library) were scanned by 2 independent researchers. The funnel plot, Egger's regression and Begg and Mazumdar's rank correlation test were used to determine publication bias. Cohen's $d$ was used to measure the effect size.

Results. Four studies were included in the meta-analysis; a total of 3 polymorphisms (rs2274327, rs2274328, rs2274333) and a total of 13 polymorphism models were analyzed. According to Egger's regression and the Begg and Mazumdar's test, the meta-analysis had no significant publication bias $(p>0.05)$. The highest susceptibility effect was noticed in the rs2274328 (AA vs CC) model ( $d=0.18$; $95 \%$ CI (confidence interval): $-1.77,2.13)$, but this effect was not significant $(p=0.237)$, and the highest protective effect was observed in the rs2274328 (AA vs AC) model ( $d=-0.13,95 \% \mathrm{Cl}:-1.36,1.11)$, but this effect was not significant, either $(p=0.195)$. No association was found between any of the polymorphism models and dental caries $(p>0.05)$.
\end{abstract}

Conclusions. Even though CAVI plays an important role in the buffering of saliva, it was shown that polymorphisms in the CA VI gene did not affect the process of dental caries.

Key words: single-nucleotide polymorphism, meta-analysis, caries susceptibility, dental caries resistance, human genome

Słowa kluczowe: polimorfizm pojedynczego nukleotydu, metaanaliza, podatność na próchnicę, odporność na próchnicę zębów, ludzki genom 


\section{Introduction}

Dental caries is one of the most common chronic diseases in the world and it can be affected by many factors, such as dietary habits, bacterial flora, fluoride intake, tooth position and morphological characteristics, oral hygiene, and amount and composition of saliva. ${ }^{1,2}$ Although there are many environmental factors affecting dental caries, some individuals seem to be more prone to the formation of dental caries. This suggests that genetic factors, in addition to environmental factors, play an important role in the pathogenesis of dental caries.

Many genetic studies in the literature have analyzed the effects of genetic variances, such as single-nucleotide polymorphisms (SNPs), on dental caries. The studies have focused on genes encoding proteins that are related to mineralization, the immune system, taste sensation, and saliva. ${ }^{3-6}$ Saliva is a complex body fluid containing essential protective components; it can regulate $\mathrm{pH}$ in the oral cavity due to its buffering capacity. ${ }^{7,8}$ With regard to the functions of saliva, various studies have investigated the effects of gene polymorphisms related to salivary proteins, such as C-type lysozyme, beta-defensin-1, lactotransferrin, carbonic anhydrase VI (CA VI), mucin, and proline-rich proteins (PRPs). ${ }^{9}$

Carbonic anhydrase (CA) is a zinc-containing metalloenzyme which catalyzes the reversible hydration of carbon dioxide. Especially, CA plays an important role in the regulation of $\mathrm{pH}$, and in the transport of liquids and ions. ${ }^{10}$ In mammals, 11 isozymes of CA have been identified. Four are cytosolic isozymes (I, II, III, and VII), 4 are membrane-bound (IV, IX, XII, and XIV), 2 are present in mitochondria (VA and VB), and 1 is a secretory isozyme (VI). Carbonic anhydrase VI is considered to greatly participate in the buffering of saliva, ion transport, the regulation of $\mathrm{pH}$, secretory processes, and saliva production.

To date, according to our knowledge, there has been no meta-analysis to synthesize the effects of the $C A V I$ gene polymorphisms on dental caries. This study aimed to perform a meta-analysis to synthesize the results of studies that investigated these effects.

\section{Material and methods}

\section{Guidance and eligibility criteria}

In this study, we abided by the guidance of the Preferred Reporting Items for Systematic Reviews and Meta-Analyses (PRISMA) statement. ${ }^{11}$ All studies that examined deciduous tooth caries (decayed, missing and filled teeth DMFT) or permanent tooth caries (dmft) were included in the meta-analysis. In cases when there was no more than 1 study on a polymorphism, the relevant polymorphism was not included in the analysis. Additionally, studies that did not calculate the DMFT/dmft index as a caries index were excluded. Studies that did not present the frequencies of genotype and phenotype polymorphisms clearly were also excluded. Studies published in English before 2019 were included. Letters to the editor, case reports, commentaries, and reviews were excluded from the meta-analysis.

\section{Information sources and search strategy}

Electronic databases (PubMed, Web of Science, Scopus, and Cochrane Library) were scanned by 2 independent researchers. Related Medical Subject Headings (MeSH) terms and text words ('gene' OR 'genome' OR 'genetic' OR 'polymorphism' OR 'carbonic anhydrase' AND 'dental' OR 'tooth' OR 'decay' OR 'caries' OR 'saliva') were used in our search strategy. The reference list of each of the studies obtained was carefully reviewed to access subject-related studies. Additionally, recent articles citing the obtained studies were found.

\section{Study selection and data collection process}

The titles and abstracts of the obtained studies were evaluated by 2 different researchers. The same studies retrieved from multiple databases were defined as single studies. Additionally, we contacted the authors to provide their articles in case the full-text access was not allowed. Polymorphisms investigated in no more than 1 study in the literature were excluded from the meta-analysis. Studies to be included in the meta-analysis were determined by a unanimous decision of the researchers.

\section{Publication bias and quality assessment}

Egger's regression and Begg and Mazumdar's rank correlation test were used in assessing publication bias. The quality assessment was performed by 2 researchers based on the modified Newcastle-Ottawa Scale (NOS), employed in previous meta-analyses related to polymorphisms. ${ }^{12}$ The scores on the scale range from 0 (the worst) to 10 (the best) points. In case the score of a study was $\geq 5$, it was accepted to have a low risk of bias, whereas if the score was $<5$, it was accepted to have a high risk of bias (Table 1).

\section{Summary measures and the synthesis of the results}

The David B. Wilson Meta-Essentials software, v. 1.2 (http://mason.gmu.edu/ dwilsonb/ma.html) was used for the statistical analysis of the data. Weight calculation was performed separately for each group. Cohen's $d$-value was preferred in measuring the effect size. The DMFT/dmft caries index was used as a variable. The fixed effect model (FEM) with 95\% confidence intervals (CIs) was used as the meta-analysis model. Heterogeneity was evaluated with Cochran's $Q$ and $I^{2}$ test. The significance level of the effect size was determined based on the two-tailed test. In all tests, the level of significance was set at $p<0.05$. 
Table 1. Modified Newcastle-Ottawa Scale (NOS) for the quality assessment

\begin{tabular}{|c|c|}
\hline Criteria & Score \\
\hline \multicolumn{2}{|l|}{ Representativeness of cases } \\
\hline Consecutive/randomly selected cases with a clearly defined sampling frame & 2 \\
\hline Not consecutive/randomly selected cases or without a clearly defined sampling frame & 1 \\
\hline Not described & 0 \\
\hline \multicolumn{2}{|l|}{ Source of controls } \\
\hline Population-based controls & 2 \\
\hline Hospital-based controls and/or healthy controls & 1 \\
\hline Not described & 0 \\
\hline \multicolumn{2}{|l|}{ Hardy-Weinberg equilibrium in controls } \\
\hline Hardy-Weinberg equilibrium & 2 \\
\hline Hardy-Weinberg disequilibrium & 1 \\
\hline Not available & 0 \\
\hline \multicolumn{2}{|l|}{ Genotyping examination } \\
\hline Genotyping done under blinded conditions and repeated again & 2 \\
\hline Genotyping done under blinded conditions or repeated again & 1 \\
\hline Genotyping done under unblinded conditions or not mentioned, and unrepeated & 0 \\
\hline \multicolumn{2}{|l|}{ Association assessment } \\
\hline Assessed the association between genotypes and caries with appropriate statistics and an adjustment for confounders & 2 \\
\hline Assessed the association between genotypes and caries with appropriate statistics and without an adjustment for confounders & 1 \\
\hline Inappropriate statistics used & 0 \\
\hline
\end{tabular}

\section{Results}

\section{Study selection and characteristics}

The literature review was performed between February 7, 2018 and May 10, 2019. The databases were scanned with the aforementioned queries and 5,112 papers were found (PubMed: 1,337; Web of Science: 1,903; Scopus: 1,826; and Cochrane Library: 46). This number was reduced to 2,372 after eliminating repetitive studies. The abstracts of the studies were examined and 2,244 studies that did not comply with the criteria were excluded. After thoroughly reviewing the full texts of the remaining 117 studies, 113 more studies that did not meet the metaanalysis criteria were excluded, and finally 4 studies were included in the meta-analysis (Fig. 1). The characteristics of the 4 studies published before 2019 are presented in Table 2.

\section{Publication bias and quality assessment}

According to Egger's regression and Begg and Mazumdar's test, the studies had no significant bias $(p>0.05)$ (Table 3). After the assessment of the modified NOS, all studies were found to have a low-risk of bias (Table 4).
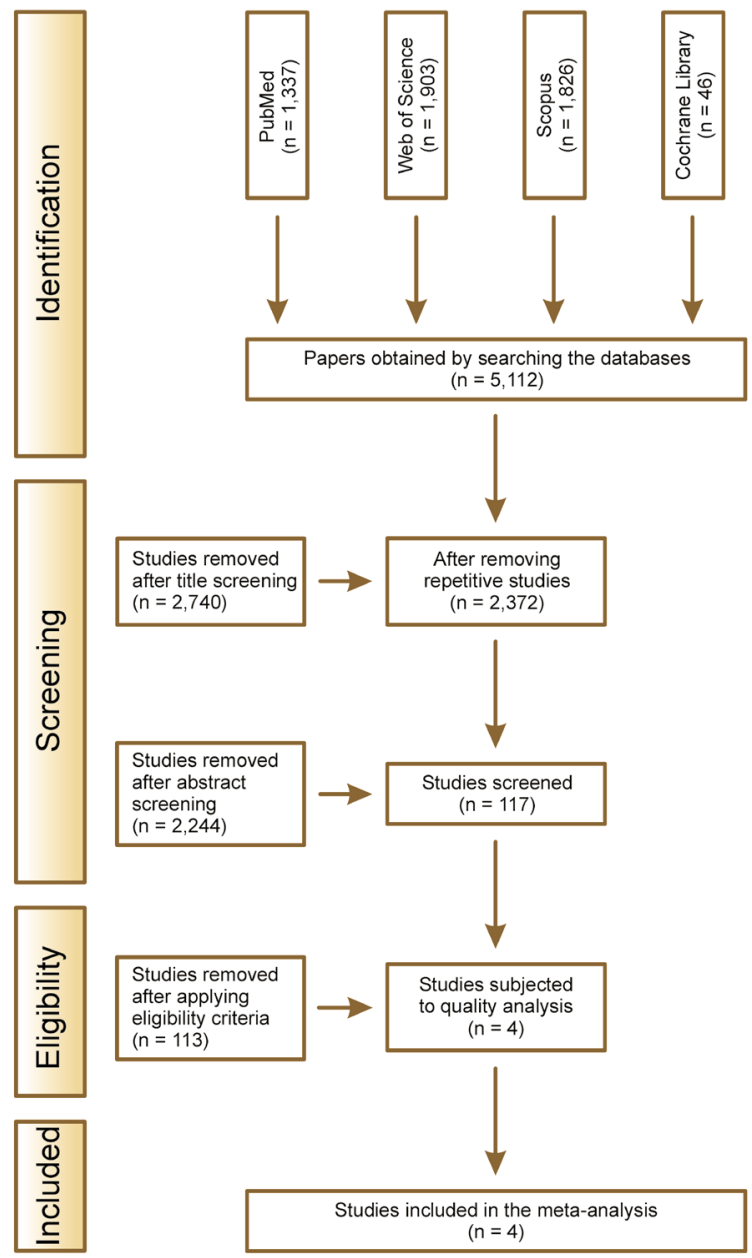

Fig. 1. Flow diagram of the studies involved in the meta-analysis 
Table 2. Features of the studies included in the meta-analysis

\begin{tabular}{|c|c|c|c|c|c|c|}
\hline No. & Study & Year & Population & $\begin{array}{c}\text { Age } \\
\text { [years] }\end{array}$ & $\begin{array}{l}\text { Caries index } \\
\text { (low; high) }\end{array}$ & Investigated genes (genetic variations) \\
\hline 1 & Peres et al. ${ }^{21}$ & 2010 & $\begin{array}{l}\text { Brazilian } \\
245 \text { children }\end{array}$ & $7-9$ & $\mathrm{dmft} / \mathrm{DMFT}(0 ; \geq 1)$ & CA6 (rs2274333, rs2274328, rs2274327) \\
\hline 2 & Li et al. ${ }^{24}$ & 2015 & $\begin{array}{l}\text { Chinese } \\
355 \text { individuals }\end{array}$ & $\begin{array}{l}51.16 \pm 9.48 \\
(\text { mean } \pm S D)\end{array}$ & $\operatorname{DMFT}(\leq 2 ; \geq 3)$ & $\begin{array}{c}\text { CA6 (rs2274328, rs17032907, rs1 1576766, rs2274333, } \\
\text { rs10864376, rs3765964, rs6680186) }\end{array}$ \\
\hline 3 & Sengul et al. ${ }^{22}$ & 2016 & $\begin{array}{l}\text { Turkish } 178 \text { children } \\
\qquad(\mathrm{M}=81, \mathrm{~F}=97)\end{array}$ & $6-16$ & $\mathrm{dmft} / \mathrm{DMFT}(0 ; \geq 1)$ & CA6 (rs2274327) \\
\hline 4 & Yildiz et al. ${ }^{23}$ & 2016 & $\begin{array}{l}\text { Turkish } \\
154 \text { individuals }\end{array}$ & $20-60$ & $\mathrm{DMFT}(\leq 5 ; \geq 14)$ & CA6 (rs2274327) \\
\hline
\end{tabular}

M - males; F - females; SD - standard deviation; dmft/DMFT - the decayed, missing and filled teeth index, related to permanent/deciduous tooth caries.

Table 3. Meta-analysis model, the heterogeneity assessment and publication bias

\begin{tabular}{|c|c|c|c|c|c|c|c|c|c|}
\hline Genetic marker (model) & Meta-analysis model & $\mathrm{n}$ & $Q$ & $p Q$ & $R^{2}$ & $\tau^{2}$ & $\tau$ & EG & BG \\
\hline rs2274327 (CC vs TT) & FEM & 3 & 1.87 & 0.392 & $<0.01$ & $<0.01$ & $<0.01$ & 0.341 & 0.059 \\
\hline rs2274327 (CC vs CT) & FEM & 3 & 2.22 & 0.330 & 0.10 & $<0.01$ & 0.07 & 0.752 & 0.301 \\
\hline rs2274327 (C vs T) & FEM & 2 & 0.13 & 0.718 & $<0.01$ & $<0.01$ & $<0.01$ & NC & 0.159 \\
\hline rs2274327 (CC vs CT+TT) & FEM & 3 & 2.19 & 0.335 & 0.09 & $<0.01$ & 0.06 & 0.567 & 0.301 \\
\hline rs2274327 (CC+CT vs TT) & FEM & 3 & 2.37 & 0.306 & 0.16 & 0.01 & 0.10 & 0.543 & 0.301 \\
\hline rs2274328 (AA vs CC) & FEM & 2 & 0.14 & 0.712 & $<0.01$ & $<0.01$ & $<0.01$ & $\mathrm{NC}$ & 0.159 \\
\hline rs2274328 (AA vs AC) & FEM & 2 & $<0.01$ & 0.999 & $<0.01$ & $<0.01$ & $<0.01$ & NC & 0.159 \\
\hline rs2274328 (AA vs AC+CC) & FEM & 2 & 2.50 & 0.114 & 0.60 & 0.03 & 0.17 & NC & 0.159 \\
\hline rs2274328 (AA+AC vs CC) & FEM & 2 & 0.10 & 0.754 & $<0.01$ & $<0.01$ & $<0.01$ & NC & 0.159 \\
\hline rs2274333 (AA vs GG) & FEM & 2 & 0.15 & 0.699 & $<0.01$ & $<0.01$ & $<0.01$ & NC & 0.159 \\
\hline rs2274333 (AA vs AG) & FEM & 2 & 0.45 & 0.500 & $<0.01$ & $<0.01$ & $<0.01$ & NC & 0.159 \\
\hline rs2274333 (AA vs AG+GG) & FEM & 2 & 0.19 & 0.662 & $<0.01$ & $<0.01$ & $<0.01$ & NC & 0.159 \\
\hline rs2274333 (AA+AG vs GG) & FEM & 2 & 0.42 & 0.519 & $<0.01$ & $<0.01$ & $<0.01$ & NC & 0.159 \\
\hline
\end{tabular}

FEM - fixed effect model; $\mathrm{n}$ - number of included studies; EG - Egger's regression ( $p$-value); BG - Begg and Mazumdar's rank correlation test ( $p$-value); $\mathrm{NC}$ - not calculated.

Table 4. Quality assessment of the studies with the modified Newcastle-Ottawa Scale (NOS)

\begin{tabular}{|c|c|c|c|c|c|c|c|}
\hline No. & Study & $\begin{array}{c}\text { Representativeness } \\
\text { of cases }\end{array}$ & $\begin{array}{c}\text { Source } \\
\text { of controls }\end{array}$ & $\begin{array}{l}\text { Hardy-Weinberg } \\
\text { equilibrium in controls }\end{array}$ & $\begin{array}{l}\text { Genotyping } \\
\text { examination }\end{array}$ & $\begin{array}{l}\text { Association } \\
\text { assessment }\end{array}$ & Score \\
\hline 1 & Peres et al. ${ }^{21}$ & 1 & 2 & 0 & 1 & 2 & 6 \\
\hline 2 & Li et al. ${ }^{24}$ & 1 & 1 & 2 & 1 & 2 & 7 \\
\hline 3 & Sengul et al. ${ }^{22}$ & 1 & 2 & 2 & 1 & 2 & 8 \\
\hline 4 & Yildiz et al. ${ }^{23}$ & 1 & 1 & 0 & 1 & 2 & 5 \\
\hline
\end{tabular}

\section{Results of individual studies and the synthesis of the results}

A total of 3 polymorphisms were included in the study and a total of 13 polymorphism models were analyzed. The number of studies in any analysis ranged from 2 to 3 . No significant heterogeneity existed in any of the analyses $\left(p_{Q}>0.05\right)$ (Table 3$)$. Therefore, in all analyses, FEM was employed.

In rs2274327, the highest susceptibility effect was noted for the rs2274327 ( $\mathrm{C}$ vs T) model $(d=0.08$; $95 \% \mathrm{CI}$ : $-1.03,1.19)$ and the protective effect was observed only in the rs2274327 $(\mathrm{CC}+\mathrm{CT}$ vs TT) model $(d=-0.01$;
95\% CI: $-0.56,0.54)$, but this effect was too low and nonsignificant $(p=0.944)$. In rs2274328, the highest susceptibility effect was noticed in the rs2274328 (AA vs CC) model $(d=0.18 ; 95 \% \mathrm{CI}:-1.77,2.13)$, but this effect was not significant ( $p=0.237$ ), and the highest protective effect was observed in the rs2274328 (AA vs AC) model $(d=-0.13 ; 95 \% \mathrm{CI}:-1.36,1.11)$, but this effect was not significant, either $(p=0.195)$. In rs2274333, all of the effects were protective and the highest protective effect was reported for the rs2274333 (AA vs AG) model $(d=-0.10$; 95\% CI: $-1.34,1.15)$, but this effect was also non-significant $(p=0.330)$. No association was found between any of the polymorphism models and dental caries $(p>0.05)$ (Fig. 2). 


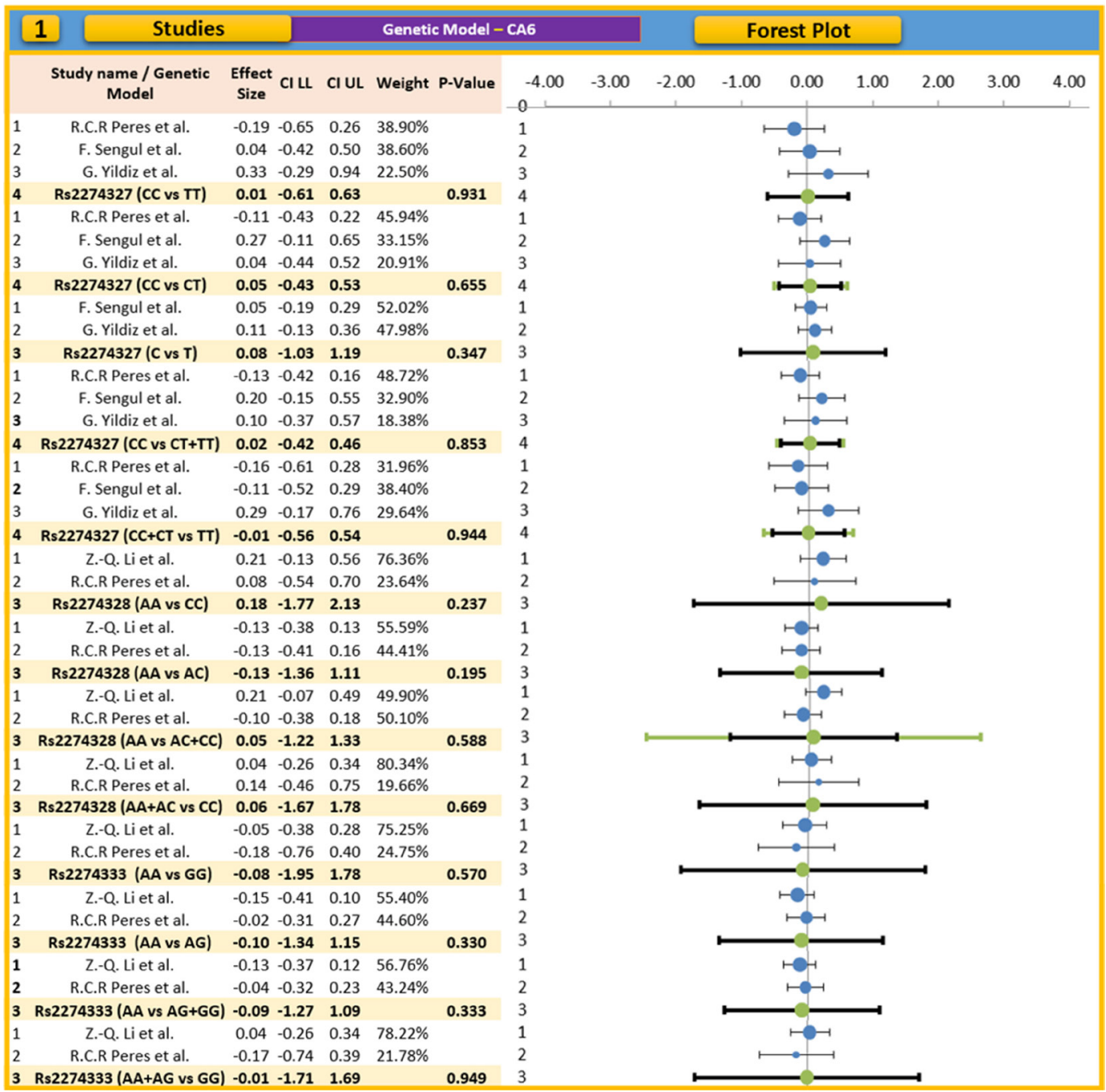

Fig. 2. Effect sizes of the polymorphisms of the carbonic anhydrase (CAVI) gene compared to the wild-type and forest plot presentation

\section{Discussion}

Several measures of the effect size have been recommended for meta-analyses, such as Pearson's correlation coefficient $r$, Cohen's $d$ or the odds ratio (OR). We preferred Cohen's $d$ in this meta-analysis. While the value of 0.00 indicates no association, $(+)$ indicates that the related polymorphism is associated with susceptibility to dental caries and (-) indicates that the related polymorphism is associated with protection against dental caries. According to Cohen's statistic, $d=0.2(\mathrm{OR} \approx 2.3)$, $d=0.5(\mathrm{OR} \approx 8.07)$ and $d=0.8(\mathrm{OR} \approx 28.25)$ indicate that the effect size is small, medium and large, respectively. ${ }^{13}$ The value of $p_{Q}<0.05$ and high $I^{2}$ values indicate that the meta-analysis has significant heterogeneity, and when heterogeneity is high in studies, the random effect model (REM) ought to be preferred. However, in this meta-analysis, none of the analyses showed heterogeneity, so we preferred FEM. Furthermore, deciduous and permanent tooth caries was not evaluated in subgroups due to the small numbers of studies examining the same polymorphisms.
Saliva plays an important role in oral homeostasis, and alterations in salivary secretion may cause oral infections and caries. Saliva contains inorganic compounds and various proteins that influence conditions in the oral cavity. The salivary buffering capacity has its share in protecting the tooth surface from caries. ${ }^{7}$ Carbonic anhydrase VI is part of the defense system of saliva, increasing the buffering capacity by catalyzing the reaction of carbon dioxide. ${ }^{14}$ In the literature, various studies have investigated the effect of CA VI on dental caries. Öztürk et al. performed a study on young adults, and they found no association between dental caries and CA VI concentration. ${ }^{15}$ However, Kivelä et al., Frasseto et al. and Szabó reported that there was an association between low CA VI concentration and a higher caries index. ${ }^{16-18}$ Esberg et al. performed a study on Swedish adolescents to determine the relationship between dental caries and variations in the $C A V I$ gene. ${ }^{19}$ In their study, it was found that the $C A V I$ gene polymorphisms, such as rs10864376 (T), rs3737665 (T) and rs12138897 (G), and the TTG haploblock of $C A V I$ are associated with Streptococcus mutans colonization, overall microbiota composition and dental caries. ${ }^{19}$ 
In the literature to date, only 5 studies have examined the relationship between the $C A V I$ exon 2 polymorphisms and dental caries. In the study of Yarat et al., which was performed on 44 Turkish subjects, no significant negative correlation was obtained between DMFT and CA activity, and no correlation was found between SNPs and the salivary buffering capacity. ${ }^{20}$ Similarly, Peres et al. investigated 3 different polymorphisms (rs2274333 A>G, rs2274328 $\mathrm{A}>\mathrm{C}$ and rs2274327 $\mathrm{C}>\mathrm{T}$ ) in 245 Brazilian schoolchildren, and no association was found between the rs2274333 $\mathrm{A}>\mathrm{G}, \mathrm{rs} 2274328 \mathrm{~A}>\mathrm{C}$ and $\mathrm{rs} 2274327 \mathrm{C}>\mathrm{T}$ polymorphisms and dental caries. ${ }^{21}$ However, they found that the rs2274327 $\mathrm{C}>\mathrm{T}$ polymorphism decreased the salivary buffering capacity. ${ }^{21}$ In another study, performed on 178 Turkish children by Sengul et al., no correlation was found between rs2274327 and dental caries. ${ }^{22}$ In the same year, Yildiz et al. performed their study on Turkish adults, and no association was found between rs2274327 and dental caries, ${ }^{23}$ similarly to other studies. Li et al. investigated in their study 7 different SNPs (rs2274328, rs17032907, rs11576766, rs2274333, rs10864376, rs3765964, and rs6680186) related to CA VI and they found an association only in the rs17032907 genetic variant, which suggested that the rs17032907 polymorphism might be associated with dental caries susceptibility. ${ }^{24}$

In the present meta-analysis, 4 different studies were included. The study of Yarat et al. was not included due to insufficient knowledge about the frequencies of genotypes. ${ }^{20}$ In the literature, there were 3 studies related to the rs2274327 polymorphism, and 2 studies related to the rs2274328 and rs2274333 polymorphisms. In any polymorphism model, no association could be obtained between the rs2274327, rs2274328 and rs2274333 polymorphisms and dental caries.

\section{Conclusions}

Although CA VI plays an important role in the buffering of saliva, it was found that polymorphisms in the $C A V I$ gene do not affect the process of dental caries. Due to an inadequate number of studies in the literature, we could only examine the rs2274327, rs2274328 and rs2274333 polymorphisms. Furthermore, due to an inadequate number of studies, the power of the meta-analysis was lower. In further studies, we recommend that researchers investigate also other polymorphisms related to the $C A V I$ gene. Additionally, we recommend the separation of the $\mathrm{dmft}$ and DMFT variables as subgroups as the number of studies increases.

\section{ORCID iDs}

Omer Hatipoglu (1) https://orcid.org/0000-0002-4628-8551 Faruk Saydam (1) https://orcid.org/0000-0003-2358-8719

\section{References}

1. Watt RG. Strategies and approaches in oral disease prevention and health promotion. Bull World Health Organ. 2005;83(9):711-718.

2. Anderson M. Risk assessment and epidemiology of dental caries: Review of the literature. Pediatr Dent. 2002;24(5):377-385.

3. Azevedo LF, Pecharki GD, Brancher JA, et al. Analysis of the association between lactotransferrin (LTF) gene polymorphism and dental caries. J Appl Oral Sci. 2010;18(2):166-170.

4. Bayram M, Deeley K, Reis MF, et al. Genetic influences on dental enamel that impact caries differ between the primary and permanent dentitions. Eur J Oral Sci. 2015;123(5):327-334.

5. Brancher JA, Pecharki GD, Doetzer AD, et al. Analysis of polymorphisms in the lactotransferrin gene promoter and dental caries. Int J Dent. 2011;2011:571726.

6. Izakovicova Holla L, Borilova Linhartova P, Lucanova S, et al. GLUT2 and TAS1R2 polymorphisms and susceptibility to dental caries. Caries Res. 2015;49(4):417-424.

7. de Almeida Pdel V, Grégio AM, Machado MA, de Lima AA, Azevedo LR. Saliva composition and functions: A comprehensive review. J Contemp Dent Pract. 2008;9(3):72-80.

8. Hara AT, Zero DT. The caries environment: Saliva, pellicle, diet, and hard tissue ultrastructure. Dent Clin North Am. 2010;54(3):455-467.

9. Lips A, Antunes LS, Antunes LA, et al. Salivary protein polymorphisms and risk of dental caries: A systematic review. Braz Oral Res. 2017;31:e41.

10. Goto T, Shirakawa H, Furukawa Y, Komai M. Decreased expression of carbonic anhydrase isozyme II, rather than of isozyme VI, in submandibular glands in long-term zinc-deficient rats. Br J Nutr. 2008;99(2):248-253.

11. Moher D, Liberati A, Tetzlaff J, Altman DG. Preferred reporting items for systematic reviews and meta-analyses: The PRISMA statement. Int J Surg. 2010;8(5):336-341.

12. Guo C, Wen L, Song JK, et al. Significant association between interleukin-10 gene polymorphisms and cervical cancer risk: A metaanalysis. Oncotarget. 2018;9(15):12365-12375.

13. Field AP, Gillett R. How to do a meta-analysis. Br J Math Stat Psychol. 2010;63(Pt 3):665-694.

14. Kimoto $M$, Kishino $M$, Yura $Y$, Ogawa Y. A role of salivary carbonic anhydrase VI in dental plaque. Arch Oral Biol. 2006;51(2):117-122.

15. Öztürk LK, Furuncuoğlu H, Atala MH, Uluköylü O, Akyüz S, Yarat A. Association between dental-oral health in young adults and salivary glutathione, lipid peroxidation and sialic acid levels and carbonic anhydrase activity. Braz J Med Biol Res. 2008;41(11):956-959.

16. Kivelä J, Parkkila S, Parkkila AK, Rajaniemi H. A low concentration of carbonic anhydrase isoenzyme $\mathrm{VI}$ in whole saliva is associated with caries prevalence. Caries Res. 1999;33(3):178-184.

17. Frasseto F, Parisotto TM, Peres RC, Marques MR, Line SR, Nobre Dos Santos M. Relationship among salivary carbonic anhydrase VI activity and flow rate, biofilm $\mathrm{pH}$ and caries in primary dentition. Caries Res. 2012;46(3):194-200.

18. Szabó I. Carbonic anhydrase activity in the saliva of children and its relation to caries activity. Caries Res. 1974;8(2):187-191.

19. Esberg A, Haworth S, Brunius C, Lif Holgerson P, Johansson I. Carbonic anhydrase 6 gene variation influences oral microbiota composition and caries risk in Swedish adolescents. Sci Rep. 2019;9(1):452.

20. Yarat A, Ozturk LK, Ulucan K, Akyuz S, Atala H, Isbir T. Carbonic anhydrase $\mathrm{VI}$ exon 2 genetic polymorphism in Turkish subjects with low caries experience (preliminary study). In Vivo. 2011;25(6):941-944.

21. Peres RC, Camargo G, Mofatto LS, et al. Association of polymorphisms in the carbonic anhydrase 6 gene with salivary buffer capacity, dental plaque $\mathrm{pH}$, and caries index in children aged 7-9 years. Pharmacogenomics J. 2010;10(2):114-119.

22. Sengul F, Kilic M, Gurbuz T, Tasdemir S. Carbonic anhydrase VI gene polymorphism rs2274327 relationship between salivary parameters and dental-oral health status in children. Biochem Genet. 2016;54(4):467-475.

23. Yildiz G, Ermis RB, Calapoglu NS, Celik EU, Türel GY. Gene-environment interactions in the etiology of dental caries. J Dent Res. 2016;95(1):74-79.

24. Li ZQ, Hu XP, Zhou JY, Xie XD, Zhang JM. Genetic polymorphisms in the carbonic anhydrase $\mathrm{VI}$ gene and dental caries susceptibility. Genet Mol Res. 2015;14(2):5986-5993. 